\title{
POHL, Manfred, SCHNEIDER, Andrea H., VIAG Aktiengesellschaft. 1923-1998, Vom Staatsunternehmen zum internationalen Konzern
}

Hervé Joly

\section{(2) OpenEdition}

Édition électronique

URL : http://journals.openedition.org/ifha/1429

DOI : $10.4000 /$ ifha. 1429

ISSN : 2198-8943

Éditeur

IFRA - Institut franco-allemand (sciences historiques et sociales)

Référence électronique

Hervé Joly, « POHL, Manfred, SCHNEIDER, Andrea H., VIAG Aktiengesellschaft. 1923-1998, Vom Staatsunternehmen zum internationalen Konzern », Revue de l'IFHA [En ligne], Date de recension, mis en ligne le 01 janvier 1999, consulté le 22 septembre 2020. URL : http://journals.openedition.org/ifha/ 1429 ; DOI : https://doi.org/10.4000/ifha.1429

Ce document a été généré automatiquement le 22 septembre 2020.

(CIFHA 


\title{
POHL, Manfred, SCHNEIDER, Andrea H., VIAG Aktiengesellschaft. 1923-1998, Vom Staatsunternehmen zum internationalen Konzern
}

\author{
Hervé Joly
}

Cette histoire de la société VIAG, publiée à l'occasion du 75e anniversaire de sa création, illustre bien l'évolution très positive qui caractérise depuis quelques années l'histoire d'entreprise »institutionnelle« en Allemagne, sous l'impulsion justement du nouveau président de la Gesellschaft für Unternehmensgeschichte signataire de ce livre, tout en en montrant les limites importantes. Il n'était en effet pas habituel qu'une histoire officielle d'entreprise consacre un long chapitre de plus de 100 pages à la période nazie et juge avec sévérité le comportement des dirigeants de l'époque. Même si l'auteur reconnaît que les seules sources centrales qu'il a utilisées restent insuffisantes pour en avoir une vision précise, l'utilisation de la main d'œuvre forcée est évoquée sans complaisance: les mesures prises par l'entreprise pour améliorer le ravitaillement des ouvriers étrangers de l'usine d'aluminium de Lauta n'auraient pas ainsi été inspirées par des considérations humanitaires, mais par le seul souci de les maintenir en état de travailler. De même, la défense en juillet 1945 d'un dirigeant selon laquelle l'activité de l'entreprise serait largement restée de nature "pacifique« est jugée, au regard des augmentations de la production réalisées dans le cadre de l'économie de guerre et de l'utilisation importante de travailleurs forcés et de prisonniers, comme de la "peinture en rose« (schönfärberig). Même une grande figure de l'économie allemande comme Ludger Westrick, dirigeant de VIAG puis après la guerre Secrétaire d'État au Ministère de l'Économie dans les gouvernements Adenauer, n'en sort pas indemne. S'il n'était pas membre du parti nazi et s'il n'existerait pas d'indication d'un comportement criminel direct, l'auteur souligne qu'il était nécessairement informé de l'existence de travailleurs forcés et des mauvais traitements qu'ils subissaient. Même s'il est regrettable que l'implication de l'entreprise dans la politique d'»aryanisation" ne soit pas mieux évoquée - on apprend seulement au 
détour d'un chapitre sur l'après-guerre que VIAG se retrouve en 1952 confrontée à une demande de restitution par la famille Petschek de participations minières récupérées en 1939 -, l'évolution reste remarquable pour des publications de ce genre qui ne faisaient traditionnellement preuve d'aucun recul par rapport aux discours patronaux de justification. Il reste cependant que ce type de »livre-anniversaire « continue de reposer sur une évidente instrumentalisation de l'historien par l'entreprise commanditaire. La volonté d'inscrire l'entreprise actuelle dans une longue histoire est largement artificielle: jusqu'à sa privatisation en 1988, VIAG n'était qu'un portefeuille assez disparate et fluctuant de participations industrielles détenues par le Reich puis par l'État fédéral. Intituler le premier chapitre »Un Konzern se forme« ne reflète pas la réalité d'une direction centrale visiblement faible. De même, le choix de prolonger l'étude historique jusqu'à la période actuelle débouche inévitablement sur une perte de distance critique: les dernières pages relèvent plus du dépliant publicitaire. Et lorsqu'il y a appréciation critique des stratégies orientées vers l'aluminium des dirigeants dans les années soixante-dix et quatre-vingt, l'historien semble se faire de manière un peu malsaine l'instrument d'un règlement de compte au profit de la nouvelle direction issue de la branche bavaroise d'énergie électrique. Il faut enfin souligner que le style de l'écriture du livre s'apparente parfois plutôt à celui d'un rapport administratif.

Hervé JOLY 